\title{
Genotyping of isolates included in the description of a novel species should be mandatory
}

The ad hoc committee for the re-evaluation of the species definition in bacteriology encouraged researchers to base a species description on more than a single strain and to apply DNA profiling (i.e. genotyping) as a method of discrimination at the subspecies level (Stackebrandt et al., 2002). Genotyping avoids a species being defined on the basis of isolates that could belong to the same strain. This may be critical for isolates recovered from the same source and/or site, where different strains or multiple isolates of the same strains may co-exist. This letter aims to support the committee's recommendation by highlighting the need for the use of genotyping techniques in the description of novel taxa. To illustrate this, we investigated the three most recently described species of Aeromonas. These are: Aeromonas culicicola, described on the basis of the type strain MTCC $3249^{\mathrm{T}}$, isolated from the midgut of the mosquito Culex quinquefasciatus, and strains $\mathrm{SH}$ and $\mathrm{SLH}$, both from the mosquito Aedes aegyptii (Pidiyar et al., 2002); Aeromonas simiae, described on the basis of two strains (CIP $107798^{\mathrm{T}}$ and CIP 107797) recovered from the faeces of the monkey Macaca fascicularis (Harf-Monteil et al., 2004); and Aeromonas molluscorum, described on the basis of five strains recovered from bivalve molluscs (Miñana-Galbis et al., 2004). In the studies describing A. culicicola and A. simiae, genotyping techniques were not applied, while they were in the study of A. molluscorum.

We genotyped all available strains of the species mentioned above using enterobacterial repetitive intergenic consensus sequence (ERIC)-PCR, a method that has been shown previously to be highly discriminatory for Aeromonas (Sechi et al., 2002; Soler et al., 2003; Szczuka \& Kaznowski, 2004; Aguilera-Arreola et al., 2005). The primers and conditions were those of Soler et al. (2003). This method proved that the two strains SH and SLH of A. culicicola showed

the same pattern (Fig. 1a), as was also the case for the two strains of $A$. simiae (Fig. 1b). Random amplification of polymorphic DNA (RAPD) analysis and pulsed-field gel electrophoresis (PFGE) (data not shown) further confirmed this. Furthermore, a re-evaluation of the hydrolysis of aesculin showed that the two strains of A. simiae are indistinguishable, contradicting the findings of Harf-Monteil et al. (2004). In contrast, the five strains of A. molluscorum showed individual ERIC-PCR patterns (Fig. 1c), which confirmed previous amplified fragment length polymorphism (AFLP) results (Miñana-Galbis et al., 2004). In conclusion, in the cases of A. culicicola and A. simiae, where no typing methods were included in the original publications (Pidiyar et al., 2002; Harf-Monteil et al., 2004), two isolates of a single strain were included in the species description.

(a)

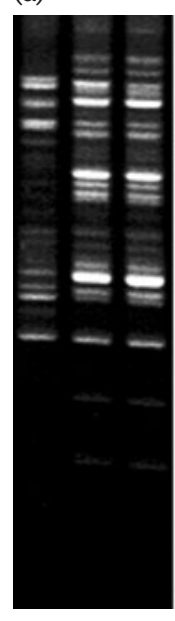

(b)

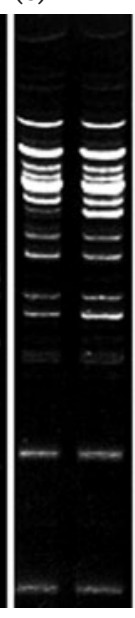

(c)

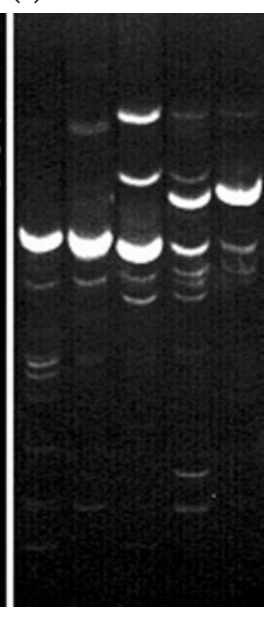

Fig. 1. ERIC-PCR patterns of Aeromonas strains. (a) A. culicicola strains MTCC $3249^{\top}$, SH and $\mathrm{SLH}$; (b) $A$. simiae strains CIP 107797 and CIP $107798^{\top}$; (c) A. molluscorum strains CECT $5864^{\top}$, CECT 5867, CECT 5865, CECT 5866 and CECT 5868 (from left to right).
Since the discriminatory power of typing methods varies among bacterial genera or species, the genotyping technique(s) employed should be that proven to be useful for the specific taxa under investigation. If no previous comparative analysis of typing methods exists, several techniques should be applied simultaneously, introducing a control strain to recognize the most discriminatory method (Buczolits et al., 2002).

\section{Acknowledgements}

The Spanish Ministry of Health (FIS03/1183) supported this research. We would like to thank Drs Pidiyar, Harf-Montiel, Esteve and Lorén for kindly providing isolates.

\section{Maria José Figueras, ${ }^{1}$ Anabel Alperi, ${ }^{1}$ Josep Guarro ${ }^{1}$ and Antonio J. Martínez- Murcia $^{2}$}

\section{${ }^{1}$ Unitat de Microbiologia, Facultat de Medicina i Ciències de la Salut, Universitat Rovira i Virgili, Sant Llorenç 21, 43201 Reus, Spain \\ ${ }^{2}$ Molecular Diagnostic Center and Universidad Miguel Hernández, Orihuela, 03312 Alicante, Spain}

Correspondence: Maria José Figueras (mariajose.figueras@urv.cat)

\section{Aguilera-Arreola, M. G., Hernandez- Rodriguez, C., Zuniga, G., Figueras, M. J. \& Castro-Escarpulli, G. (2005). Aeromonas hydrophila clinical and environmental ecotypes as revealed by genetic diversity and virulence genes. FEMS Microbiol Lett 242, 231-240.}

Buczolits, S., Denner, E. B. M., Vybiral, D., Wieser, M., Kämpfer, P. \& Busse, H. J. (2002). Classification of three airborne bacteria and proposal of Hymenobacter aerophilus sp. nov. Int J Syst Evol Microbiol 52, 445-456.

Harf-Monteil, C., Le Flèche, A., Riegel, P., Prévost, G., Bermond, D., Grimont, P. A. D. \& Monteil, H. (2004). Aeromonas simiae sp. nov., isolated from monkey faeces. Int J Syst Evol Microbiol 54, 481-485. 
Miñana-Galbis, D., Farfán, M., Fusté, M. C. \& Lorén, J. G. (2004). Aeromonas molluscorum sp. nov., isolated from bivalve molluscs. Int J Syst Evol Microbiol 54, 2073-2078.

Pidiyar, V., Kaznowski, A., Narayan, N. B., Patole, M. \& Shouche, Y. S. (2002). Aeromonas culicicola sp. nov., from the midgut of Culex quinquefasciatus. Int J Syst Evol Microbiol 52, 1723-1728.

Sechi, L. A., Deriu, A., Falchi, M. P., Fadda, G. \& Zanetti, S. (2002). Distribution of virulence genes in Aeromonas spp. isolated from Sardinian waters and from patients with diarrhoea. J Appl Microbiol 92, 221-227.

Soler, L., Figueras, M. J., Chacón, M. R., Guarro, J. \& Martínez-Murcia, A. J. (2003). Comparison of three molecular methods for typing Aeromonas popoffii isolates. Antonie van Leeuwenhoek 83, 341-349.

Stackebrandt, E., Frederiksen, W., Garrity, G. M. \& 10 other authors (2002). Report of the ad hoc committee for the re-evaluation of the species definition in bacteriology. Int J Syst Evol Microbiol 52, 1043-1047.

Szczuka, E. \& Kaznowski, A. (2004). Typing of clinical and environmental Aeromonas sp. strains by random amplified polymorphic DNA PCR, repetitive extragenic palindromic PCR, and enterobacterial repetitive intergenic consensus sequence PCR. J Clin Microbiol 42, 220-228. 